

\section{Sumário}

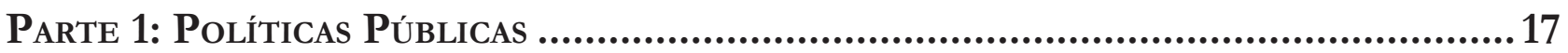

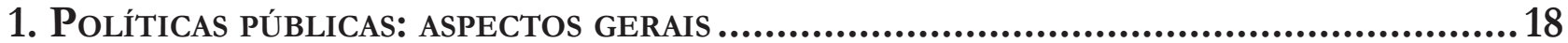

UM MODELO POLÍTICO DE IMPLEMENTAÇÃO PARA AS POLÍTICAS PÚBLICAS: OS PAPÉIS DO DIREITO E DOS JURISTAS.

William H. Clune III

Evaluación de las obras públicas en gobiernos locales en MÉxico: Desafíos de LaS POLÍTICAS PÚBLICAS DE PARTICIPACIÓN CIUDADANA

Louis Valentin Mballa e Arturo Bermúdez Lara

Paternalismo libertário e políticas públicas: intervenção e transparênCia

Marcia Carla Pereira Ribeiro e Victor Hugo Domingues

2. Políticas públicas E COVID-19

LiMITES E POSSIBILIDADES PARA O USO SECUNDÁRIO DE DADOS PESSOAIS NO PODER PÚBLICO: LIÇÕES DA PANDEMIA.

Miriam Wimmer

EFICIÊNCIA DAS POLÍTICAS DE INOVAÇÃO NOS SETORES INDUSTRIAIS BRASILEIROS: SUGESTÕES PARA A CRISE DA COVID-19

Michelle Márcia Viana Martins e Chrystian Soares Mendes

CoMPLIANCE EM TEMPOS DE CALAMIDADE PÚbLICA: ANÁLISE SOBRE A FLEXIBILIZAÇÃo DA TRANSPARÊNCIA DE DADOS E INFORMAÇÕES DURANTE O ENFRENTAMENTO DA COVID-19 NO BrasiL

Luciana Cristina da Conceição Lima, Alcindo Fernandes Gonçalves, Fernando Cardoso Fernandes Rei e Cláudio Benevenuto de Campos Lima

3. Políticas públicas e accountability

ACCOUNTABility E DESENHO INSTITUCIONAL: UM “PONTO CEGO" NO DIREITO PÚBLICO BRASILEIRO

Danielle Hanna Rached

ESTRATÉGIAS REGULATÓRIAS DE COMBATE À CORRUPÇÃo 
O controle e a avaliação pelo Tribunal de Contas da União das políticas públicas IMPLEMENTADAS POR DESONERAÇÕES TRIBUTÁRIAS NO BRASIL

Vinicius Garcia e Carlos Araújo Leonetti

4. Políticas públicas em Matéria de SAÚde

A livre opÇão pela Cesariana: um "NUdge Às aVessas". .268

Bruna Menezes Gomes da Silva e Júlio Cesar de Aguiar

AUTISMO: ASPECTOS JURÍDICOS DA ACESSIBILIDADE E RESPEITO

Fabiana Barrocas Alves Farah e Danilo Fontenele Sampaio Cunha

SAÚdE E DOENÇAS RARAS: ANÁLISE DA JUDICIALIZAÇÃo DO ACESSO AO TRATAMENTO E SUAS LIMITAÇÕES.

Danilo Henrique Nunes e Lucas de Souza Lehfeld

5. OUTRAS POLÍTICAS PÚBLICAS EM ESPÉCIE

REGUlAÇÃO DAS ÁGUAS: UMA ANÁLISE EMPÍRICA DA PRODUÇÃo NORMATIVA DOS ÓRGÃOS REGULADORES FEDERAIS

Bianca Borges Medeiros Pavão, Natasha Schmitt Caccia Salinas e Thauany do Nascimento Vigar

“LET THE ALGORITHM DECIDE": IS HUMAN DIGNITY AT STAKE?.

Marcela Mattiuzzo

DAS ACEPÇÕES DOS DIREITOS DOS REFUGIADOS ÀS VOZES SILENCIADAS NAS POLÍTICAS PÚBLICAs371 Thaís Araújo Dias e Monica Mota Tassigny

Planejamento familiar: “inimigo" a Ser combatido, “aliado” libertador ou falso "AMIGO"?

Vinicius Ferreira Baptista

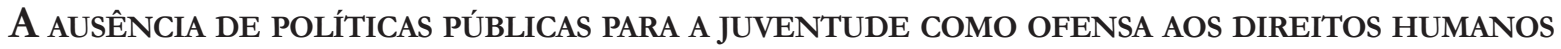
William Timóteo e llzver de Matos Oliveira

AnÁlise CÊniCa dos feminicídios em Curitiba: propostas preventivas e repressivas ....433 Ticiane Louise Santana Pereira, Octahydes Ballan Junior e Antonio Henrique Graciano Suxberger

ORIGIN AND CONSEQUENCES OF THE WAR ON DRUGS. FROM THE UNITED STATES TO ANDEAN COUNTRIES

Silvio Cuneo e Nicolás Oxman 
Trabalho Decente: comportamento Ético, política pública ou Bem JuRIDiCamente TUTELADO?.

Silvio Beltramelli Neto e Mônica Nogueira Rodrigues

El FINAL DE UNA POLÍtica PÚBLICA: ANÁLISIS DEL CICLO POLÍTICO DEL PROYECTO DESTINOS INDUCTORES PARA EL DESARROLLO TURISTICO REGIONAL (DIDTR) - BRASIL. .496

María Belén Zambrano Pontón, Magnus Luiz Emmendoerfer e Suely de Fátima Ramos Silveira

Alternativa tecnológica para COMPensaÇão de CRÉditos de ICMS: ESTUdo de Caso da VIABILIDADE DO USO DE DLT EM NOTA FISCAL ELETRÔNICA .520

Danielle Mendes Thame Denny, Roberto Ferreira Paulo e Fernando Crespo Queiroz Neves

Parte 2: Temas Gerais

A construção do Direito Humano ao Alimento no plano internacional. 551 Tatiana de A. F. R. Cardoso Squeff

Grupos vUlNERABles de ESPECIAL PROTECCIÓN POR PARTE DEL INSTITUTO NACIONAL DE Derechos Humanos (INDH) ¿EN QUIÉN PODRÍA Y DEBERÍA ENFOCARSE EN BASE A LA DOCTRINA Y A LA EXPERIENCIA COMPARADA IBEROAMERICANA?

Juan Pablo Díaz Fuenzalida

El SUFRAGIO ELECTRÓNICO COMO ALTERNATIVA AL SUFRAGIO TRADICIONAL: LUCES Y SOMBRAS DE UN DEBATE RECURRENTE 595

David Almagro Castro, Felipe Ignacio Paredes Paredes e Edgardo Lito Andres Cancino

Cognoscibilidade E CONTROLE SOCIAL dA TRANSPARÊNCIA PÚbliCA SOB A ÉGIDE DA DEMODIVERSIDADE: ESTUDO EMPÍRICO DE PORTAIS ELETRÔNICOS MINISTERIAIS LATINOAMERICANOS

Ana Carolina Campara Verdum, Leonardo Fontana Trevisan e Rosane Leal da Silva

DESAFIOS E BENEFÍCIOS DA INTELIGÊNCIA ARTIFICIAL PARA O DIREITO DO CONSUMIDOR 655 Sthéfano Bruno Santos Divino

QUEM TEM MEDO DA RESPONSABILIZAÇÃo SUBJETIVA? As TEORIAS DA CONDUTA E DA IMPUTAÇÃO, PARA UM DIREITO ADMINISTRATIVO SANCIONADOR CONSTITUCIONALIZADO...........................690 Sandro Lúcio Dezan e Paulo Afonso Cavichioli Carmona

A INSUfiCiÊNCIA dE TRIBUTAÇÃo COMO FUNDAMENTO PARA O AFASTAMENTO DA RESERVA DO POSSÍVEL NA GARANTIA DO MÍNIMO EXISTENCIAL E DA DIGNIDADE HUMANA. 711 Dione J. Wasilewski e Emerson Gabardo 


\title{
Autismo: aspectos jurídicos da acessibilidade e respeito*
}

\section{Autism: legal aspects of accessibility and respect}

\author{
Fabiana Barrocas Alves Farah** \\ Danilo Fontenele Sampaio Cunha***
}

\section{Resumo}

Trata-se de reflexão necessária sobre os direitos das pessoas autistas na busca de inclusão social, apresentando a legislação aplicável e sugerindo acréscimos. O estudo foi feito por meio de pesquisa bibliográfica em que foram abordadas as dificuldades de implementação das leis e estatutos já existentes, principalmente para aceitação das características das pessoas com deficiência e autistas, diante de suas estereotipias. Demonstraremos o que é o transtorno do espectro autista e a necessidade de melhor compreensão para posterior aceitação e inclusão dos autistas, para busca de uma posição digna como seres humanos, numa sociedade moderna e universalista. Por fim, chegamos a um entendimento de que a existência de políticas públicas sobre o assunto é a chave para se alcançar essa dignidade.

Palavras-chave: Autismo. Pessoa com Deficiência. Inclusão. Acessibilidade. Respeito.

\section{Abstract}

This is a necessary reflection on the rights of autistic people in the pursuit of social inclusion, presenting the applicable legislation and suggesting additions. The study was carried out by means of bibliographic research which addressed the difficulties of implementing existing laws and statutes, mainly in accepting the characteristics of people with disabilities and autistic people, in view of their stereotypes. We will demonstrate what is the autism spectrum disorder and the need for better understanding for later acceptance and inclusion of autists, in the search for a dignified position as human beings, in a modern and universalist society. Finally, we came to an understanding that the existence of public policies on the subject is the key to achieving this dignity.

Keywords: Autism. Person with Disability. Inclusion. Acessibility. Respect.

** Mestranda em Direito Privado pelo Centro Universitário 7 de Setembro (UNI7-CE). Especialista em Direito Militar (FTP-TO). Advogada e Fisioterapeuta.

E-mail: fabifarah@hotmail.com

*** Doutor em Direito (PUC-SP). Juiz Federal da $11^{a}$ Vara do Ceará. Professor Doutor do Centro Universitário 7 de Setembro (UNI7CE).Email: daniloffc@uol.com.br

* Recebido em 25/01/2020 Aprovado em 04/06/2020 


\section{Introdução}

A dignidade da pessoa humana está sempre em discussão na sociedade moderna, mas a procura pela efetivação dos direitos de pessoas autistas, acometidas por um transtorno que traz prejuízo na comunicação, no desenvolvimento social e comportamental, se depara cotidianamente com a discriminação, o preconceito, a exclusão e o desrespeito que atingem não apenas os diretamente envolvidos, mas também por seus pais e parentes, em um contínuo de estigmatizações e limitações.

A intolerância diante da diversidade é exteriorizada por situações cotidianas predominantemente discriminatórias que vitimizam e desqualificam uma minoria desejosa de estar inserida socialmente.

A exclusão dos autistas, e das pessoas com deficiência em geral, decorre de fatores além da própria limitação existente, constatando-se que, apesar de sua evolução formal, a legislação aplicável necessita de forte conscientização popular a fim de efetivamente romper o preconceito.

Pessoas que desconhecem o tema podem acreditar que os esforços de inserção igualitária dessas pessoas são desnecessários por ser impossível, fixando-se no que se tem como estereotipias mais aparentes, mormente nas reações de violência e autoflagelo. No entanto, a inclusão acaba sendo um ganho tanto para o autista quanto para quem o inclui, porque a experiência de vivenciar diferenças propicia, além de sensibilização humanista, a reavaliação dos nossos valores e princípios, na percepção de que todos somos, ou seremos, pessoas com deficiência em alguma área ou atividade, principalmente decorrentes da idade.

O desconhecimento sobre como é a vida de um autista e seu modo de perceber e reagir ao mundo, bem como os efeitos e intensidades com que os estímulos ambientais o afetam, é um dos aspectos vivenciais mais marcantes do seu cotidiano em relação. De igual maneira, não é raro médicos, por não conhecerem ou não identificarem as diversas variáveis do espectro autista, encaminharem o indivíduo ainda sem diagnóstico para um colega psiquiatra ou neurologista para tratá-lo de sintoma comum a outras morbidades.

As lutas pelo respeito à condição autista, a compreensão dos aspectos únicos de seu comportamento e a tolerância com as manifestações de suas crises, na tentativa de evitar que sejam hostilizados ou negligenciados pelo poder público e pela sociedade, é uma realidade de milhares de pessoas, independentemente de seu grau de estudo ou condição social.

O presente estudo tem base teórica e doutrinária utilizando bibliografia selecionada sobre as questões sociais vivenciadas pelas pessoas com transtorno do espectro do autismo (TEA) e seus familiares. Constitui, também, pesquisa exploratória, pois pretende examinar problemas e situações do cotidiano dos autistas, e demonstrar como é a realidade dessa vivência. Além disso, utiliza o método qualitativo, porque concentra no caráter subjetivo dessa busca dos autistas por respeito aos seus direitos e espaço na sociedade. Utiliza o método dedutivo, porque apresenta diversas formas de reflexão sobre as atitudes das pessoas envolvidas buscando, concluir algo acerca dessa exclusão.

Este trabalho está estruturado nos seguintes tópicos principais, em que se expõe, inicialmente e de maneira resumida, a legislação que trata dos direitos das pessoas com deficiência, inclusive a lei específica para o autista.

O tópico posterior enfrenta a questão da (in) tolerância diante do autismo, expondo a visão real da sociedade e suas reações frente às manifestações do comportamento incomum do autista, suas estereotipias e as circunstâncias necessárias para serem compreendidos e terem garantidos os seus direitos.

O último tópico apresenta as divisões e subdivisões dos níveis do transtorno do espectro autista, realçando a importância da inclusão no desenvolvimento comportamental desses indivíduos.

As conclusões serão apresentadas ao final para compreensão que, mesmo um indivíduo com limitações, dentro de seus espectros e níveis, é plenamente capaz de adaptação social, sendo dever de todos facilitar tal direito constitucional e legal. 


\section{As pessoas com deficiência e a legislação}

Pode-se afirmar que as pessoas com deficiência sempre sofreram discriminações ao longo da história e foram oriundas, em sua maior parte, da simples ignorância sobre a diversidade natural, fatores genéticos e doenças, ou por intolerância ao diferente, insensibilidade ante o aparentemente fora do padrão ou mera intransigência com as singularidades. Tais percepções, desde cedo, influenciaram a própria legislação e seu brando desenvolvimento.

Na Roma antiga, havia leis que reconheciam os direitos de um recém-nascido, desde que a criança não nascesse antes do $7^{\circ}$ mês de gestação, nem apresentasse algum sinal ou distorção da forma humana, sendo prevista a morte imediata por afogamento caso fosse entendido que não possuía viabilidade. ${ }^{1}$

Alguns historiadores acreditam que aqueles com deficiência que conseguiam escapar da execução sumária eram submetidos a um "mercado especial" em Roma, dedicado à compra e venda de pessoas com deformidades físicas, sem membros, com nanismo ou gigantismo, além de hermafroditas. ${ }^{2}$

Apenas após o começo da Era Cristã é que se iniciou um olhar diferenciado em relação às pessoas com deficiência e aos mais pobres e humildes. As instituições ligadas ao atendimento desses necessitados cresceram incentivadas pela iniciativa dos bispos e freiras nos mosteiros da época, que também recebiam recém-nascidos órfãos ou rejeitados. ${ }^{3}$

Paradoxalmente, na Idade Média, foi implementada a "Nau dos Loucos", que nada mais era do que uma embarcação que levava as pessoas com deficiência intelectual para um destino qualquer, sem prévio conhecimento. O objetivo era retirá-las das ruas, ou seja, evitar que maculassem, com suas presenças, a linha de visão das pessoas. ${ }^{4}$

Entre os séculos V e XV, principalmente no período da Inquisição, a própria Igreja Católica perseguiu e descriminou as deficiências físicas, mentais e as malformações congênitas, considerando-as "castigo de Deus" e, assim, excluía as pessoas com deficiência da caridade, mesmo quando as doenças graves e incapacitantes se espalharam pela Europa Medieval, o que gerou grande número de sequelados miseráveis e estigmatizados. ${ }^{5}$

O Renascimento trouxe a consideração dos direitos universais, baseado no avanço científico e na consciência filosófica humanística e, diante desse novo entendimento, entre os séculos XVI e XVII, as pessoas com deficiência foram assunto de preocupação específica, consolidando a necessidade de proteção maior, superando-se em parte a condição marginal de então. ${ }^{6}$

Ao longo dos séculos, as práticas sociais de atendimentos direcionadas às pessoas com deficiência, ao redor do mundo, voltaram-se para uma discreta humanização comportamental demonstrando evolução das civilizações e avanço na preocupação com a saúde e os direitos humanos. ${ }^{7}$

\footnotetext{
ALVES, José Carlos Moreira. Direito Romano. 15. ed. Rio de Janeiro: Editora Forense, 2012. p. 15-28. v. I.

2 ANATALINO, João. O Deficiente na Cultura Greco-Romana- A Óptica Espartana. São Paulo: Recanto das Letras, 2017. Código do texto: T6141362. Disponível em: https://www.recantodasletras.com.br/artigos-de-educacao/6141362. Acesso em: 25 abr. 2019.

3 GARCIA, Vinicius Gaspar. As pessoas com deficiência na bistória do mundo. Rio de Janeiro: Bengala Legal, 2011. Disponível em: http://www.bengalalegal.com/pcd-mundial. Acesso em: 15 jun. 2019.

4 FOUCAULT, Michel. História da Loucura na Idade Clássica. Trad. José Teixeira Coelho Netto. São Paulo: Perspectiva, 1978. p. 13.

5 GARCIA, Vinicius Gaspar. As pessoas com deficiência na bistória do mundo. Rio de Janeiro: Bengala Legal, 2011. Disponível em: http://www.bengalalegal.com/pcd-mundial. Acesso em: 15 jun. 2019.

${ }_{6}$ No século XVI, médicos defendiam a ideia de que as pessoas com deficiência mental eram assim por um acidente hereditário ou de má formação genética, e não acreditavam que pudessem evoluir. Naquela época, caberia aos médicos, e não à igreja, sobre a vida e o destino desses indivíduos.

GARCIA, Vinicius Gaspar. Panorama da inclusão das pessoas com deficiência no mercado de trabalho no Brasil. Trab. educ. saúde, Rio de Janeiro, v. 12, n. 1, p. 167, abr. 2014. Disponível em: http://www.scielo.br/scielo.php?script=sci_arttext\&pid=S198177462014000100010\&lng=pt\&nrm=iso. Acesso em: 18 jun. 2019. http://dx.doi.org/10.1590/S1981-77462014000100010.
} 
Nos Estados Unidos, por volta de 1811, uma atenção específica foi dada para garantir, aos combatentes marinheiros ou fuzileiros navais com sequelas físicas e mentais, o direito à moradia e alimentação. ${ }^{8}$ No período da Segunda Guerra Mundial, os mutilados, e os incapacitados física e mentalmente, causaram grande preocupação, fazendo surgir documentos internacionais de proteção. ${ }^{9}$

A Constituição Política do Império, de 1824, excluía, em seu artigo $8^{\circ}$, I, o exercício de direitos políticos pela incapacidade física ou moral, sem maiores explicações a respeito de quais incapacidades se referia. ${ }^{10}$

Em 1891, a Constituição da República dos Estados Unidos do Brasil manteve a suspensão dos direitos em virtude da incapacidade física ou moral, e a Constituição de 1934 restringiu os direitos pela incapacidade civil absoluta, sem mencionar a questão física, mas trazia termos discriminatórios, como "órfãos, abandonados, libertinos, alienados e outros tipos de doentes sociais", além dos "pretos ou pardos", "débeis ou atrasados", bem como estimulava a educação engênica no intuito de "melhorar as gerações futuras" (Art.137) e limitava a entrada de imigrantes como garantia da integração étnica e capacidade física e civil (Art.121, $\int 6^{\circ}$ ), apesar de rejeitar toda e qualquer discriminação, igualando todos perante a lei (artigos 113, I e 121, $\left.\$ 6^{\circ}\right) . .^{11}$

As Constituições de 1937, de 1946, de 1967 mencionaram as pessoas com deficiência no que diz respeito à infância e juventude e à invalidez e suas consequências advindas dos acidentes de trabalho, mas sempre trazendo as exceções relacionadas à "sanidade física" dos portugueses, em relação ao direito de naturalização brasileira. $\mathrm{Na}$ Constituição de 1937, os magistrados perderiam as garantias da vitaliciedade em razão de invalidez comprovada, o que fora modificado, excluindo essa restrição somente na Constituição de $1946 .{ }^{12}$

Em 1948, a Declaração Universal dos Direitos Humanos (Resolução ONU n. ${ }^{\circ} 217$ A (III), de 10 de dezembro de 1948) tratou da promoção do respeito aos direitos e liberdades entre os povos dos Estados-Membros e dos territórios sob sua jurisdição, garantindo, em seu artigo $1^{\circ}$, que todos os seres humanos nascem livres e iguais em dignidade e em direitos. ${ }^{13}$

Somente com a Emenda Constitucional n. 1 de 1969, que alterou o texto da Constituição de 1967, o Brasil passou a tratar da educação de excepcionais, no intuito de integrá-los, mas não os incluir (artigo 175, $\int 4^{\circ}$ da EC 1, 1969). ${ }^{14}$

$\mathrm{Na}$ época, o passo maior foi dado a partir da Emenda Constitucional n. ${ }^{\circ} 12$, de 1978, que assegurava, em seu artigo único, a melhoria das condições sociais dos "deficientes", que era o termo usado à época. ${ }^{15}$

\footnotetext{
8 Desde cedo foi dada atenção específica para os ex-combatentes com deficiência nos EUA. Depois da guerra, foi construído na Filadélfia, em 1867, o Lar Nacional para Soldados Voluntários Deficientes.

9 NISHIYAMA, Adolfo Mamoru; TEIXEIRA, Carla Noura. A evolução histórica da proteção das pessoas com deficiência nas Constituições brasileiras: os instrumentos normativos atuais para a sua efetivação. Revista de Direito Privado, São Paulo, v. 17, n. 68, p. 226, ago. 2016.

10 CAMPANHOLE, Adriano; CAMPANHOLE; Hilton Lôbo. Todas as Constituições do Brasil- compilação dos textos, notas, revisão e índices. São Paulo: Atlas, 1971. p. 582. Disponível em: http://biblioteca2.senado.gov.br:8991/F/?func=itemglobal\&doc_ library $=$ SEN01\&doc_number $=000012720$. Acesso em: 14 jun. 2019.

11 AGUILAR FILHO, Sidney. Educação, autoritarismo e eugenia = exploração do trabalho e violência à infância desamparada no Brasil (19301945). 2011. Tese (Doutorado) - Faculdade de Educação Universidade Estadual de Campinas, Campinas, São Paulo, 2011. Disponível em: http://www.repositorio.unicamp.br/handle/REPOSIP/251194. 2011; e BRASIL. Constituição da República Federativa dos Estados Unidos do Brasil. Rio de Janeiro. RJ. 1934. Disponível em: http://www.planalto.gov.br/ccivil_03/constituicao/constituicao34. htm. Acesso em: 14 jun. 2019.

12 BRASIL. Constituição dos Estados Unidos do Brasil. Rio de Janeiro. RJ. 1937. Disponível em: http://www.planalto.gov.br/ccivil_03/ Constituicao/Constituicao37.htm. Acesso em: 14 jun. 2019 BRASIL. Constituição dos Estados Unidos do Brasil. Rio de Janeiro. RJ. 1946. Disponível em: https://www2.camara.leg.br/legin/fed/consti/1940-1949/constituicao-1946-18-julho-1946-365199-publicacaooriginal-1-pl.html. Acesso em: 14 jun. 2019; BRASIL. Constituição da República Federativa do Brasil. Brasília. DF. 1967. Disponível em: http://www.planalto.gov.br/ccivil_03/constituicao/constituicao67.htm. Acesso em: 14 jun. 2019.

13 RIO GRANDE DO SUL. Governo do Estado. Fundação de Articulação e Desenvolvimento de Políticas Públicas para Pessoas com Deficiência e com Altas Habilidades no Rio Grande do Sul - FADERS. Legislação Internacional. Rio Grande do Sul. Disponível em: http://www.faders.rs.gov.br/legislacao/6. 2019. Acesso em: 18 jun. 2019.

14 BRASIL. Emenda Constitucional n. 1, de 17 de outubro de 1969. Brasília. DF. 1969. Disponível em: http://www.planalto.gov.br/ ccivil_03/constituicao/Emendas/Emc_anterior1988/emc01-69.htm. Acesso em: 14 jun. 2019.

15 BRASIL. Emenda Constitucional n. 12, de 17 de outubro de 1978. Brasília. DF. 1978. Disponível em: http://www.planalto.gov.br/
} 
A promulgação da Constituição de 1988 trouxe, em diversos capítulos e dispositivos, a inserção da proteção específica dos direitos das pessoas com deficiência, incluindo em 2003 a Emenda Constitucional n. ${ }^{\circ}$ 41, que versou sobre a invalidez dos servidores públicos, e a Emenda Constitucional n. ${ }^{\circ} 45$, de 2004, que permitiu ao Congresso Nacional aprovar e incorporar tratados e convenções internacionais sobre direitos humanos, com status de emendas constitucionais, seguindo, para isso, todo o procedimento regular ${ }^{16}$, o que possibilitou que a Convenção da ONU sobre os direitos das pessoas com deficiência e seu Protocolo Facultativo, assinados em Nova Iorque em 2007, passassem a ser equivalentes às emenda constitucionais.

No intervalo entre a Constituição Federal de 1988 do Brasil e a Convenção da ONU de 2007, surgiram várias legislações internacionais em defesa dessa minoria, como as Normas para Equiparação de Oportunidades para Pessoas com Deficiência da ONU n. ${ }^{\circ}$ 48/96, de 20 de dezembro de 1993, que estabeleceram medidas para a igualdade, acessibilidade, educação, emprego, dentre outros direitos; a Carta para o Terceiro Milênio, de 09 de setembro de 1999, em Londres, que estabeleceu medidas para proteger os direitos das pessoas com deficiência mediante o apoio ao empoderamento e a inclusão em todos os aspectos da vida. ${ }^{17}$

Em termos trabalhistas, a evolução dos tratados e convenções também é recente, sendo editada em de 25 de junho de 1958, a Convenção OIT 111, que trouxe a proibição de discriminação em matéria de emprego e profissão referente a salário e critérios de admissão; em 20 de junho de 1983, a Convenção OIT 159 tratou sobre reabilitação profissional e emprego de pessoas "deficientes", ratificada no Brasil pelo Decreto n. ${ }^{\circ}$ 129, de 22 de maio de 1991 e a Convenção OIT 168, de 01 de junho de 1988, tratou sobre a promoção de emprego e proteção ao desemprego (ratificada no Brasil pelo Decreto 2.682, de 21 de julho de 1998).

No que diz respeito à criança em geral, incluindo a com deficiência, podemos citar, em termos de convenções, declarações e tratados, a Convenção sobre os Direitos da Criança adotada pela Assembleia Geral da ONU em 20 de novembro de 1989; a Convenção Interamericana da Guatemala, de 28 de maio de 1999, para eliminar todas as formas de discriminação contra as pessoas com deficiência; a Declaração de Sundeberg (Torremolinos, Espanha), de 07 de novembro de 1981, sobre acesso à educação, cultura e informação; a Declaração de Jomtien (Tailândia), de 09 de março de 1990, chamada Declaração Mundial sobre Educação para Todos; a Declaração de Salamanca, de 10 de julho de 1994, sobre educação especial; Declaração de Santiago (Chile), de 19 de abril de 1998, sobre discriminação e integração de grupos vulneráveis à vida política e econômica; Declaração de Quito, de 24 de julho de 1998, sobre direitos econômicos, sociais e culturais na América Latina; Declaração de Madri, 23 de março de 2002, em comemoração ao ano de 2003 como sendo o ano europeu das pessoas com deficiência e Declaração de Sapporo (Japão), de 18 de outubro de 2002, sobre, acessibilidade, inclusão, genética, bioética, educação inclusiva e vida independente.

Depois dessas conquistas, uma significativa quantidade de legislações ordinárias adaptou-se visando aprimorar os direitos e garantias especificamente em defesa das pessoas com deficiência, abrangendo desde a integração social até o direito de ingressar e permanecer com cão-guia em ambientes de uso coletivo, sendo cristalizadas com a Lei Brasileira de Inclusão (LBI) ou Estatuto da Pessoa com Deficiência (Lei 13.146 de 2015)..$^{18}$

Encontramos, em seu artigo $2^{\circ}$, a definição de pessoa com deficiência como sendo aquela que tem impedimento de longo prazo de natureza física, mental, intelectual ou sensorial, o qual, em interação com uma

ccivil_03/constituicao/Emendas/Emc_anterior1988/emc12-78.htm. Acesso em: 14 jun. 2019.

16 BRASIL. Emenda Constitucional n. 41, de 19 de dezembro de 2003. Brasília. DF. 2003. Disponível em: http:/ /www.planalto.gov.br/ ccivil_03/constituicao/constituicao.htm; e BRASIL. Emenda Constitucional n. 45, de 30 de dezembro de 2004. Brasília. DF. 2004. Disponível em: http://www.planalto.gov.br/ccivil_03/constituicao/emendas/emc/emc45.htm. Acesso em: 14 jun. 2019.

17 RIO GRANDE DO SUL. Governo do Estado. Fundação de Articulação e Desenvolvimento de Políticas Públicas para Pessoas com Deficiência e com Altas Habilidades no Rio Grande do Sul - FADERS. Legislação Internacional. Rio Grande do Sul. Disponível em: http://www.faders.rs.gov.br/legislacao/6. Acesso em: 18 jun. 2019.

18 NISHIYAMA, Adolfo Mamoru; TEIXEIRA, Carla Noura. A evolução histórica da proteção das pessoas com deficiência nas Constituições brasileiras: os instrumentos normativos atuais para a sua efetivação. Revista de Direito Privado, São Paulo, v. 17, n. 68, p. 232-233, ago. 2016. 
ou mais barreiras, pode obstruir sua participação plena e efetiva na sociedade em igualdade de condições com as demais pessoas. ${ }^{19}$

No caso da pessoa com Transtorno do Espectro do Autismo, ou apenas Autista, a Lei Ordinária Federal n. ${ }^{\circ}$ 12.764/2012 instituiu a Política Nacional de Proteção dos Direitos das Pessoas com Transtorno do Espectro do Autismo, decorrente de uma sugestão legislativa apresentada por uma associação defensora da causa. Esta lei foi batizada de "Lei Berenice Piana", referindo-se a uma mãe de pessoa autista que luta incansavelmente, como tantas outras, pelos direitos deles. ${ }^{20}$

A Lei n. ${ }^{\circ}$ 13.977/2020, atualizando a Lei Berenice Piana, criou a Carteira de Identificação da Pessoa com Transtorno do Espectro Autista (CIPTEA), em que ressalta a atenção prioritária e integral nos atendimentos em serviços públicos e privados reforçando o que garante a Lei Brasileira de Inclusão e a Constituição Federal de 1988. Essa lei foi batizada de "Lei Romeo Mion", homenageando o filho do artista Marcos Mion que possui o transtorno.

Além disso, a expedição do documento é gratuita e indica o Código Internacional de Classificação da doença (CID), assim como dados pessoais do autista e seu responsável legal, devendo estar sempre atualizado para, inclusive, permitir o registro estatístico de pessoas acometidas pelo autismo no Brasil. Questiona-se se o documento tem prazo de validade de cinco anos, como se o transtorno tivesse cura. Acredita-se que a intenção seja tão somente para mantê-lo atualizado. ${ }^{21}$

Verifica-se, portanto, que, ao longo do tempo, o direito à acessibilidade foi sendo garantido e é hoje considerado um direito fundamental, onde promover a inclusão das pessoas com deficiência na sociedade, objetiva garantir dignidade e o exercício da cidadania, dando independência, autonomia, liberdade e condições de igualdade a todos. ${ }^{22}$

\section{0 (Des) respeito diante da deficiência e do autismo}

Apesar de terem ocorrido muitas mudanças legislativas, inclusive no que diz respeito à acessibilidade de transporte, prédios e equipamentos públicos, ainda são verificadas atitudes de preconceito e discriminação, além de diversas formas de violência, quanto aos direitos à saúde, educação e profissionalização das pessoas com deficiência, sendo comum as pessoas tenderem a rejeitar comportamentos diferentes dos seus, seja no que diz respeito à simples aparência física ou à escolha do estilo de vida. ${ }^{23}$

Pode-se dizer que nossa sociedade, ainda carrega, no seu núcleo, algumas mazelas, como atitudes de um pretenso conservadorismo que, na verdade, representam apenas atraso e ausência de conhecimento, caracterizando-se, conforme Agerson Tabosa ${ }^{24}$, por se apoiar "na ignorância, ou no temor, na segurança ou no comodismo".

Em geral, ainda persiste a ideia de que tudo o que for contrário ao chamado "homem médio" ${ }^{25}$, padroni-

\footnotetext{
19 BRASIL. Lei 13.146 de 06 de julho de 2015. Estatuto da Pessoa com Deficiência. Brasília. DF. 2015. Disponível em: http://www.planalto.gov.br/ccivil_03/_ato2015-2018/2015/lei/113146.htm. Acesso em: 24 abr. 2019.

20 AMARAL, Carlos Eduardo Rios. Lei no 12.764/2012: Direitos da Pessoa com Transtorno do Espectro Autista. Revista Jus Navigandi, 2016. Disponível em: https://jus.com.br/artigos/48333/lei-n-12-764-2012-direitos-da-pessoa-com-transtorno-do-espectro-autista. Acesso em: 15 jun. 2019.

21 BRASIL. Lei 13.977 de 08 de janeiro de 2020. Lei Romeo Mion. Brasília. DF. 2020. Disponível em: http://www.planalto.gov.br/ ccivil_03/_ato2019-2022/2020/lei/113977.htm. Acesso em: 06 jun. 2020.

22 NISHIYAMA, Adolfo Mamoru; TEIXEIRA, Carla Noura. A evolução histórica da proteção das pessoas com deficiência nas Constituições brasileiras: os instrumentos normativos atuais para a sua efetivação. Revista de Direito Privado, São Paulo, v. 17, n. 68, p. 235, ago. 2016.

23 PESSOA, Amanda Carolina Santos. A diversidade brasileira, as minorias, o direito e a busca pela igualdade em contraposição às discriminações sociais. Revista do Direito Constitucional e Internacional, São Paulo, v. 106, ano. 26, p. 202, mar./abr. 2018.

24 TABOSA, Agerson. Sociologia Geral e Jurídica. Fortaleza: Qualygraf Editora e Gráfica, 2005. 600 p.

25 "Homem médio": padrão e modelo normativo e inclusivo considerado socialmente "ideal" PESSOA, Amanda Carolina Santos.
} 
zado socialmente, deve ser considerado menor, defeituoso, grotesco, incapaz, retrógrado, imperfeito, o que faz eclodir a exclusão social e, por consequência, a intolerância.

Infelizmente, ainda podemos encontrar pessoas que parecem acreditar que o convívio com as pessoas com deficiência, principalmente os autistas, retardam ou contagiam negativamente as demais, como se tivessem uma doença infecciosa terminal. Quando falamos em autismo, um dos mitos que as pessoas acreditam que caracteriza o transtorno é de que os autistas vivem num mundo próprio, isolado, interagindo somente no espaço a sua volta, mas isso não procede. ${ }^{26}$

Há relatos da oposição dos pais de crianças ditas "comuns” à convivência com autistas ou crianças com necessidades especiais, afirmando prejuízo à educação aos seus filhos, justificando a falta do progresso dos demais pela simples presença deles no mesmo ambiente escolar. Essas posturas hostis nos fazem perceber que há a necessidade de mudanças, muito mais de atitude e comportamento das pessoas, do que mesmo de estrutura física dos locais de ensino. ${ }^{27}$

$\mathrm{Na}$ verdade, existem casos ainda mais repugnantes de bullying acontecendo a cada instante pelo mundo, em vários lugares além da escola, do trabalho, da repartição pública, que vitimizam as pessoas com deficiência, principalmente os autistas, pela simples condição de serem o que são.

A maior visibilidade das pessoas com deficiência não corresponde, automaticamente, à tolerância, até porque esta, segundo Tabosa, ${ }^{28}$ está intimamente ligada à aceitação, seja positiva ou negativamente, isto é, pode-se aceitar e tolerar, tolerar sem aceitar ou aceitar sem tolerar, desdobrando-se em como o indivíduo age, pensa e sente, tudo a depender tanto da consciência e sensibilidade individual quanto da coerção exterior sobre as pessoas, podendo estar fixada ou não em lei. Assim, o que é visto, mas não tolerado ou não aceito, tende a ser rejeitado, excluído.

Aprendemos a enxergar e avaliar os outros de acordo com os traços de comportamento peculiares e preestabelecidos desde a infância, a partir da educação e do exemplo que recebemos de nossos educadores, pais ou responsáveis ${ }^{29}$, mas, mesmo parecendo difícil modificar opiniões adquiridas na infância, o respeito e a tolerância podem ser exercitados e aprendidos a qualquer tempo ${ }^{30}$. Pessoas completas e complexas são capazes de reconhecer e respeitar as outras, com seus defeitos e diferenças, sempre atuando com a razão dosada com emoção. ${ }^{31}$

Malgrado, uma deficiência física poder ser considerada comum e tolerável para algumas pessoas, com base na compaixão, ${ }^{32}$ quando se fala de direitos fundamentais, não se trata de simples aceitação, mas de verdadeiro respeito às pessoas e suas características, com implicações diretas na garantia de seus direitos.

Logo, sabendo disso e tendo interesse em eliminar atitudes discriminatórias, a sociedade deve buscar condutas menos excludentes que atravessem os obstáculos da discriminação, do preconceito e da intolerân-

A diversidade brasileira, as minorias, o direito e a busca pela igualdade em contraposição às discriminações sociais. Revista do Direito Constitucional e Internacional, São Paulo, v. 106, ano. 26, p. 202-203, mar./abr. 2018.

26 SPÍNOLA, Grasielly de Oliveira. Autismo: o ideal e o real na efetivação da decisão jurisdicional que implementa políticas públicas. Revista Brasileira de Políticas Públicas, Brasília, v. 4, n. 1, p. 55-65, 2014. Disponível em: https://www.publicacoesacademicas. uniceub.br/RBPP/article/view/2756/pdf_1. Acesso em: 22 jun. 2019.

27 SERRA, Dayse Carla Genero. Entre a esperança e o limite: um estudo sobre a inclusão de alunos com autismo em classes regulares. Tese (Doutorado) Psicologia, Pontifícia Universidade Católica do Rio de Janeiro, Rio de Janeiro, 2008. Certificação digital $\mathrm{n}^{\circ}$ 0510405/CB. Disponível em: https://www.maxwell.vrac.puc-rio.br/13415/13415_1.PDF. Acesso em: 15 jun. 2019. p. 24.

28 TABOSA, Agerson. Sociologia Geral e Jurídica. Fortaleza: Qualygraf Editora e Gráfica, 2005. p. 71-74.

29 ASPERGER, Hans. Os "psicopatas autistas" na idade infantil - Parte 1. Rev. Latinoam. Psicopat. Fund., São Paulo, p. 317-318, jun. 2015. ISSN 1415-4714.

30 PESSOA, Amanda Carolina Santos. A diversidade brasileira, as minorias, o direito e a busca pela igualdade em contraposição às discriminações sociais. Revista do Direito Constitucional e Internacional, São Paulo, v. 106, ano. 26, p. 213, mar./abr. 2018.

31 CUNHA, Danilo Fontenele Sampaio. A Justiça Sensiviel. Perspectivas incomuns e possibilidades utópicas. Rio de Janeiro: Editora Lumen Juris, 2019. p. 121.

32 A pessoa com deficiência não precisa de tolerância pela compaixão social para exercer seus direitos, precisa de respeito. 
cia, diante de todas as diversidades, para promover uma melhor convivência social. ${ }^{33}$

De igual modo, o pensamento que a suposta improdutividade do autista apresenta, como pessoa com deficiência, compromete o seu direito de exercer a cidadania ${ }^{34}$. Hans Asperger ${ }^{35}$ acredita que "igualmente essas pessoas têm o seu lugar no organismo do grupo social, espaço este que preenchem plenamente, algumas delas, talvez, de forma unica", além do que os seres humanos são indivíduos plenamente adaptáveis e capazes de desenvolver condições possíveis de inserir as diferenças na sociedade com dignidade e respeito.

Assim, na reflexão de $\operatorname{Pessoa}^{36}$, o que a sociedade não compreende é que as pessoas com deficiência, inclusive o autista, busca, inicialmente, alcançar a igualdade por meio da efetivação dos direitos constitucionais já garantidos, mas, para isso, é necessária a atuação fundamental do Direito, combatendo e punindo as injustiças e violações das leis, reforçando a necessidade da inclusão, em conjunto com a participação social, na procura da garantia da dignidade dessas pessoas por meio do respeito mútuo, na intenção de construir um mundo mais universal e menos individual.

É apenas pela compreensão do que é autismo que poderemos desenvolver maior empatia e facilitar nossas adaptações às características dessas pessoas.

\section{0 autismo e a necessidade da inclusão}

Anthony Giddens ${ }^{37}$ afirma que vivenciamos uma modernidade tardia com padrões de estilo de vida que despertam rejeição e segregação social, diminuindo, gradativamente, o contato e a aproximação entre as pessoas, sendo caracterizada pelo preconceito e discriminação.

Pode-se constatar que, apesar de as palavras "inclusão" e "acessibilidade" serem comuns nos discursos políticos e sociais, com estímulo à aceitação e convivência pacífica com a diversidade, muitas vezes certas diferenças ainda despertam exclusão por não serem aceitas com naturalidade. ${ }^{38}$

Segundo Tabosa, ${ }^{39}$ a existência do "contato" é uma condição indispensável para os processos sociais acontecerem, ou seja, o fato social advém de relações entre os seres humanos, e essas relações representam importantes processos sociais que necessitam do encontro de indivíduos e grupos, interagindo entre si, no intuito de socialização mútua, realçando o autor que o afastamento entre pessoas e grupos prejudica as trocas de experiências, renovação de conceitos e evolução das sensibilidades.

A não visibilidade das pessoas com deficiência, principalmente os autistas, pode ensejar a construção de uma minoria, ou seja, a falta de conhecimento a respeito do transtorno pode fazer com que os indivíduos com o transtorno sejam inferiorizados socialmente e tenham seus direitos não reconhecidos e aplicados. ${ }^{40}$

\footnotetext{
33 SERRA, Dayse Carla Genero. Entre a esperança e o limite: um estudo sobre a inclusão de alunos com autismo em classes regulares. Tese (Doutorado) Psicologia, Pontifícia Universidade Católica do Rio de Janeiro, Rio de Janeiro, 2008. Certificação digital $n^{\circ}$ 0510405/CB. Disponível em: https://www.maxwell.vrac.puc-rio.br/13415/13415_1.PDF. Acesso em: 15 jun. 2019.

34 Sabe-se que cada vez mais os autistas de grau leve podem ocupar papel importante na sociedade, trabalhando, construindo família e vivendo sem maiores dificuldades e dentro de suas limitações.

35 ASPERGER, Hans. Os “psicopatas autistas” na idade infantil - Parte 3. Rev. Latinoam. Psicopat. Fund., São Paulo, p. 725, jun. 2015.ISSN 1415-4714.

36 PESSOA, Amanda Carolina Santos. A diversidade brasileira, as minorias, o direito e a busca pela igualdade em contraposição às discriminações sociais. Revista do Direito Constitucional e Internacional, São Paulo, v. 106, ano. 26, p. 219-220, mar./abr. 2018.

37 GIDDENS, Anthony. Modernidade \& Identidade. Rio de Janeiro: Zahar, 2002. p.13.

38 MELO, Marilice Pereira Ruiz do Amaral. Inclusão na diversidade: a contribuição da espiritualidade e interdisciplinaridade. Educação: Fundamentos da Educação. Revista INTERESPE, São Paulo, n. 8, p. 100-102, jun. 2017. ISSN 2179-7498. Disponível em: https://www.pucsp.br/interespe/revistas/downloads/revista-8-interespe-jun-2017.pdf. Acesso em: 14 jun. 2019.

39 TABOSA, Agerson. Sociologia Geral e Jurídica. Fortaleza: Qualygraf Editora e Gráfica, 2005. p. 113-114.

40 PESSOA, Amanda Carolina Santos. A diversidade brasileira, as minorias, o direito e a busca pela igualdade em contraposição às discriminações sociais. Revista do Direito Constitucional e Internacional, São Paulo, v. 106, ano. 26, p. 204, mar./abr. 2018.
} 
Carolina Oliveira, em 2005, ${ }^{41}$ apresentou dados do Center of Deseases Control and Prevention (CDC), atestando que há um caso de autismo para cada 110 pessoas. Assim, a estimativa no Brasil é que existiam, em 2005, por volta de dois milhões de autistas inseridos em duzentos milhões de habitantes naquele ano.

De acordo com o Censo de 2010, realizado no Brasil, havia em torno de 45.624 .000 pessoas que apresentavam ao menos uma deficiência pesquisada (IBGE, 2010). Esse número representava por volta de $23,93 \%$ do total da população brasileira naquele ano, divididos nas cinco regiões em: 1,4\% no Norte; 1,7\% no Centro-Oeste; $3,2 \%$ no Sul; $7,4 \%$ no Nordeste e $9,7 \%$ no Sudeste. ${ }^{42}$

Em 1943 o médico austríaco Leo Kanner, considerado o pioneiro no ramo, descreveu a patologia utilizando o termo "Transtorno Autístico do Contato Afetivo", que apresentava um grau mais severo semelhante ao de um esquizofrênico, uma vez que os indivíduos estudados demonstravam um alheamento do mundo ao seu redor, não respondendo aos estímulos recebidos, se relacionando estreitamente apenas com objetos, não apresentando interesse em interagir socialmente. ${ }^{43}$

Kanner observou que, desde a infância (a partir dos 2 anos de vida), esses indivíduos não mantinham relação com a realidade, vivendo isoladamente num mundo interno, sem a interferência do grupo social em que faziam parte, passando a denominar a síndrome de "Autismo Infantil Precoce". A partir daí, o autor passou a selecionar os comprometimentos específicos de cada caso, em que via uns com certa inteligência preservada e, às vezes, incomum, outros com alterações de comunicação e linguagem, chegando até ao mutismo, o que refletia a imensa dificuldade de relacionamento interpessoal, como se o autismo fosse um desmembramento da esquizofrenia infantil. ${ }^{44}$

Ao longo dos anos, vários estudiosos, cientistas, médicos, psiquiatras, psicólogos e interessados no assunto buscaram demonstrar que o autismo é um quadro clínico diferenciado, mas ainda considerado uma junção de alterações psíquicas e comportamentais e sem nenhuma relação com a esquizofrenia. Porém, é uma patologia que traz prejuízo para comunicação e desenvolvimento social advindos de um comportamento alterado, avesso à mudanças, e de alterações sensoriais exacerbadas que tornam as pessoas difíceis de manter relações sociais apropriadas. ${ }^{45}$

Mesmo com uma incidência grande, somente em 1993 o autismo foi inserido na Classificação Internacional de Doenças da Organização Mundial da Saúde. Isso se deve ao fato de que ainda não há afirmação genética das causas dessa síndrome, além de ser difícil detectar com rapidez apenas por meio dos sintomas e do comportamento apresentado, pois são classificações complicadas de se especificar, dentro dos graus leve (nível 1), moderado (nível 2) e grave (nível 3) que se conhece.

Contudo, com o avanço dos estudos, esses níveis podem se subdividir em outros tantos, de acordo com as diferentes variações no comportamento de cada caso que surge, os chamados "espectros", isto é, uma

41 OLIVEIRA, Carolina. Um retrato do autismo no Brasil. Universidade de São Paulo. Revista Espaço Aberto USP, São Paulo, 2005. Disponível em: http://www.usp.br/espacoaberto/?materia=um-retrato-do-autismo-no-brasil. Acesso em: 19 jun. 2019.

42 BRASIL. Secretaria Especial dos Direitos da Pessoa com Deficiência. Resultados Preliminares da Amostra - Censo 2010. Brasília. DF. 2010. Disponível em: https://www.pessoacomdeficiencia.gov.br/app/indicadores/censo-2010. Acesso em: 19 jun. 2019.

43 RODRIGUES, Ida Janete. Habilidades viso-perceptuais e motoras na Sindrome de Asperger. 2010. Tese (Doutorado) Psicologia Clínica Instituto de Psicologia, Universidade de São Paulo, São Paulo, 2010. doi:10.11606/T.47.2010.tde-03092010-151245. Disponível em: https://teses.usp.br/teses/disponiveis/47/47133/tde-03092010-151245/publico/rodrigues2_do.pdf. Acesso em: 18 jun. 2019.

44 O termo "Autismo Infantil" seria utilizado para uma faixa etária mais jovem e em pessoas com comprometimento maior na fala e na interação social. RODRIGUES, Ida Janete. Habilidades viso-perceptuais e motoras na Síndrome de Asperger. 2010. Tese (Doutorado) Psicologia Clínica - Instituto de Psicologia, Universidade de São Paulo, São Paulo, 2010. doi:10.11606/T.47.2010.tde-03092010151245. Disponível em: https://teses.usp.br/teses/disponiveis/47/47133/tde-03092010-151245/publico/rodrigues2_do.pdf. Acesso em: 18 jun. 2019.

45 O diagnóstico do nível mais leve do transtorno é mais difícil, por que pode gerar confusão com uma simples deficiência mental ou um mero atraso generalizado que inclua a fala. RODRIGUES, Ida Janete. Habilidades viso-perceptuais e motoras na Sindrome de Asperger. 2010. Tese (Doutorado) Psicologia Clínica - Instituto de Psicologia, Universidade de São Paulo, São Paulo, 2010. doi:10.11606/T.47.2010.tde-03092010-151245. Disponível em: https://teses.usp.br/teses/disponiveis/47/47133/tde-03092010151245/publico/rodrigues2_do.pdf. Acesso em: 18 jun. 2019. 
amplitude que engloba diferentes níveis de gravidade, ${ }^{46}$ e a graduação dos níveis se dá a partir dos comprometimentos apresentados ${ }^{47}$ de acordo com a história pessoal, o momento do diagnóstico e aos cuidados oferecidos a cada um. Dessa forma, de acordo com o nível da afetação da cognição, linguagem, prejuízos comportamentais e sensoriais, sociabilidade e estereotipias - movimentos repetitivos-, pode-se dizer que não existe um autista igual a outro, o que, consequentemente, enseja a necessidade de formas variadas e adaptáveis de interação e acompanhamento.

Há várias teorias sobre alguns comportamentos percebidos nos diferentes níveis do autismo. Especula-se, por exemplo, que a inabilidade de se relacionar com outras pessoas se deve ao comprometimento da capacidade de abstração e simbolismo, como se o autista não soubesse reconhecer as emoções, faltando-lhe a capacidade para responder aos estímulos por meio de expressões, gestos ou mesmo pela linguagem. Essa atribuição dos déficits sociais é uma característica comum, inclusive uma dificuldade de perceber a si mesmo no lugar que ocupa e o que está em sua volta, sendo os tratamentos com fonoaudiólogas e terapeutas essenciais para o desenvolvimento de suas maneiras particulares e especiais de comunicação.

O autismo tem, pois, níveis de comprometimento ou espectros dos mais variados, em que, em alguns casos, os indivíduos acometidos conseguem manter uma relação com outras pessoas, são capazes de interagir, conviver socialmente e mesmo construir família e ter uma profissão, como um típico "Asperger" (espectro da síndrome de nível 1, mais leve), que, geralmente, dispõe de uma inteligência diferenciada. ${ }^{48}$

Hans Asperger, ${ }^{49}$ que, até pouco tempo atrás, batizava o espectro leve do autismo, pesquisou e escreveu, em 1943, sobre os "psicopatas autistas" na idade infantil, em que afirmou: "todo ser bumano é um ser único, irreproduzivel, indivisivel ('individuum') e, por isso, em última instância, não passivel de comparação com outros.” E continua: "[...] quando tentamos categorizar uma pessoa — que não apresenta nenbum desvio grosseiro ou anormalidade qualitativa que determina a sua personalidade como um todo - segundo uma tipologia ou forçá-la para dentro desta, a constrangemos na medida em que a avaliamos".

Os autistas Asperger, geralmente, tendem a se isolar pouco socialmente, e o transtorno desse nível é estável, o que permite uma comunicação verbal diferenciada, precoce e formal que envolve pouca empatia, diminuição leve dos aspectos afetivos e possuem interesses específicos em determinada área (geralmente ciências exatas). Porém, um aspecto que é deficitário em todos os níveis é a interação social e a deficiência ou falta de empatia, dificultando as relações interpessoais e o cumprimento espontâneo das regras sociais. Por isso, necessita de acompanhamento comportamental para ser condicionado à rotina diária e assim, poder se relacionar com mais desenvoltura. ${ }^{50}$

Nos níveis 2 e 3 (moderado à grave), há, geralmente, atraso motor, desde ao sentar quando bebê até a marcha depois de adulto. $\mathrm{O}$ autismo considerado clássico, ou seja, o que possui todos os comprometimentos neuropsicomotores associados, manifesta-se com a recusa do contato visual e físico, claramente hipersensí-

\footnotetext{
46 OLIVEIRA, Carolina. Um retrato do autismo no Brasil. Revista Espaço Aberto USP, São Paulo, 2005. Disponível em: http:// www.usp.br/espacoaberto/?materia=um-retrato-do-autismo-no-brasil. Acesso em: 19 jun. 2019.

47 RODRIGUES, Ida Janete. Habilidades viso-perceptuais e motoras na Sindrome de Asperger. 2010. Tese (Doutorado) Psicologia Clínica Instituto de Psicologia, Universidade de São Paulo, São Paulo, 2010. doi:10.11606/T.47.2010.tde-03092010-151245. Disponível em: https://teses.usp.br/teses/disponiveis/47/47133/tde-03092010-151245/publico/rodrigues2_do.pdf. Acesso em: 18 jun. 2019.

48 Os aspectos psíquicos isolados não são constantes, mas podem ser calculadas numerosas diferenças qualitativas e só devem ser comparados uns aos outros com restrições. ASPERGER, Hans. Os "psicopatas autistas" na idade infantil - Parte 1. Rev. Latinoam. Psicopat. Fund., São Paulo, p. 324-325, jun. 2015. ISSN 1415-4714.

49 ASPERGER, Hans. Os "psicopatas autistas" na idade infantil - Parte 3. Rev. Latinoam. Psicopat. Fund., São Paulo, p. 314-338, jun. 2015.ISSN 1415-4714; ASPERGER, Hans. Os "psicopatas autistas" na idade infantil - Parte 2. Rev. Latinoam. Psicopat. Fund., São Paulo, p. 519-538, jun. 2015. ISSN 1415-4714; e ASPERGER, Hans. Os “psicopatas autistas” na idade infantil - Parte 3. Rev. Latinoam. Psicopat. Fund., São Paulo, p. 704-727, jun. 2015.ISSN 1415-4714.

50 RODRIGUES, Ida Janete. Habilidades viso-perceptuais e motoras na Síndrome de Asperger. 2010. Tese (Doutorado) Psicologia Clínica Instituto de Psicologia, Universidade de São Paulo, São Paulo, 2010. doi:10.11606/T.47.2010.tde-03092010-151245. Disponível em: https://teses.usp.br/teses/disponiveis/47/47133/tde-03092010-151245/publico/rodrigues2_do.pdf. Acesso em: 18 jun. 2019.
} 
veis a ruídos ou barulhos altos,$^{51}$ diminuição significativa ou a falta de coordenação motora, apresentação de estereotipias (na fala ou em movimentos repetitivos) que, em alguns casos, também são demonstradas em si mesmos por meio de castigos físicos, pancadas e mordidas, ou seja, autoflagelo intenso, chegando muitas vezes, caso não sejam impedidos, a se mutilar (nível mais grave), como se o autista não tivesse percepção sobre seu próprio corpo e não sentisse dor, ante a inexistência das sensações de atividade muscular, ${ }^{52}$ que causa estranheza e medo nas pessoas ao redor devido à desinformação de como reagir.

Estudiosos de outra teoria, chamada "Teoria da Mente", observaram que existem dois (de muitos) mecanismos cerebrais básicos, que estabelecem uma ligação com o mundo e que detectam a intencionalidade e o direcionamento do olhar. Eles deveriam permitir que o autista construísse imagens sobre as pessoas, pois estão relativamente preservados nessa patologia, mas, para que o autista possa interpretar o comportamento dos outros e reagir a esse comportamento, ou seja, às reações que envolvam contato físico de cunho emocional (abraço, beijo), é necessário que dois outros mecanismos estejam preservados, são eles: a atenção compartilhada e a Teoria da Mente. Esses últimos que comandam os sentidos (olhar, tocar e ouvir) e o pensamento (conhecer, acreditar) apresentam-se de forma deficitária, prejudicando a normalidade dos comportamentos sociais. ${ }^{53}$

O fato de o autista apresentar déficits de cognição específicos não os impede de aprender uma forma de se reorganizar dentro da sociedade. A suposição de que a função de executar comandos, de se integrar, de responder a estímulos externos estaria limitada também a depender do grau de comprometimento do transtorno. O autista de nível mais leve pode atingir uma meta, quando estimulado, até mais rápido que uma pessoa sem a condição do autismo, da mesma forma que o de nível grave ou severo, nem ao menos tenta responder pelo simples fato de não processar nem reconhecer a informação comandada. ${ }^{54}$

Às vezes o autista chama a atenção socialmente positiva por uma das características do transtorno, o hiperfoco. Essa é a capacidade que cerca de $10 \%$ dos autistas podem desenvolver em manter intensa atenção voltada a áreas específicas de interesse, desenvolvendo habilidades e domínio sobre um tema, como idiomas, música ou ciências exatas.

Tais facilidades são, no entanto, exceções, e mesmo elas não garantem êxito ao longo da vida, sendo necessário dar visibilidade social à grande maioria desprovida de amparo terapêutico. Atualmente, o autismo é tido como um transtorno amplo, multifacetado e de difícil diagnóstico em certos casos, exatamente pelos diferentes graus que apresenta, pela variedade de alterações cerebrais, físicas e comportamentais, sendo considerado um transtorno global de desenvolvimento. ${ }^{55}$

Na verdade, é o desenvolvimento das funções cognitivas e de sua capacidade de adaptação, provenientes da relação com o meio ambiente, que faz o autista corresponder ao estímulo recebido. A percepção de que

\footnotetext{
51 ASPERGER, Hans. Os "psicopatas autistas” na idade infantil - Parte 3. Rev. Latinoam. Psicopat. Fund., São Paulo, p. 715, jun. 2015.ISSN 1415-4714.

52 O desenvolvimento e a coordenação motora de determinados autistas, mesmo que vistas como normais em alguns deles, ainda que apresentassem deambulação com movimentos rudes, eram considerados habilidosos em algumas áreas. RODRIGUES, Ida Janete. Habilidades viso-perceptuais e motoras na Síndrome de Asperger. 2010. Tese (Doutorado) Psicologia Clínica - Instituto de Psicologia, Universidade de São Paulo, São Paulo, 2010. doi:10.11606/T.47.2010.tde-03092010-151245. Disponível em: https://teses.usp.br/ teses/disponiveis/47/47133/tde-03092010-151245/publico/rodrigues2_do.pdf. Acesso em: 18 jun. 2019

53 A noção de esquema corporal advém de um sistema psicofisiológico originário nos dados sensoriais que são enviados e fornecidos pelo esquema motor, a partir da movimentação corporal realizada RODRIGUES, Ida Janete. Habilidades viso-perceptuais e motoras na Síndrome de Asperger. 2010. Tese (Doutorado) Psicologia Clínica - Instituto de Psicologia, Universidade de São Paulo, São Paulo, 2010. doi:10.11606/T.47.2010.tde-03092010-151245. Disponível em: https://teses.usp.br/teses/disponiveis/47/47133/tde03092010-151245/publico/rodrigues2_do.pdf. Acesso em: 18 jun. 2019

54 RODRIGUES, Ida Janete. Habilidades viso-perceptuais e motoras na Sindrome de Asperger. 2010. Tese (Doutorado) Psicologia Clínica Instituto de Psicologia, Universidade de São Paulo, São Paulo, 2010. doi:10.11606/T.47.2010.tde-03092010-151245. Disponível em: https://teses.usp.br/teses/disponiveis/47/47133/tde-03092010-151245/publico/rodrigues2_do.pdf. Acesso em: 18 jun. 2019.

55 FARAH, Fabiana Barrocas Alves. Autismo: o desafio da inclusão na sociedade moderna. Revista Construir Notícias, Recife, ano 20, p. 40-43, 2020. ISSN 2236-3505. Disponível em: https://www.construirnoticias.com.br/autismo-o-desafio-da-inclusao-na-sociedade-moderna/. Acesso em: 01 mar. 2020.
} 
o autista vive uma compreensão alterada do mundo e das interações, que podem até ser exacerbadas de acordo com o grau de comprometimento que a síndrome se apresenta, é que comportará o diferencial de seu desenvolvimento. ${ }^{56}$

Os sintomas podem ser observados nos primeiros meses de vida, mas podem ser muito sutis, o que dificulta a percepção dos pais, e outras condições podem ser confundidas com autismo, como atraso global no desenvolvimento intelectual, síndrome de Rett, transtorno de aprendizagem não verbal e alguns transtornos de apego reativo, daí a importância do diagnóstico precoce (art. $2^{\circ}$ III da lei 12.764/12) por equipe médica especializada para o início da reabilitação e melhor prognóstico, existindo protocolos específicos para tanto. Obviamente, qualquer teste disponível na internet e sem acompanhamento de profissionais é desaconselhável.

Apesar de serem diversas as estereotipias, as mais comuns são aversão ao contato físico e ao contato visual, hipersensibilidade à luminosidade e a sons altos, podendo ocorrer fonofobia (desconforto causado por sons específicos relacionados a seus significados emocionais), movimento pendular do corpo para frente e para trás, chacoalhar de mãos e braços ao lado do corpo, como se fosse asas, principalmente quando esses indivíduos estão felizes, ansiosos ou irritados, movimentos repetidos das mãos em frente dos olhos, andar com a ponta dos pés, ambulação de um lado para outro, ecolalia, repetição de sons, palavras ou frases emitidos por outras pessoas, aparelhos ou por si próprias, batidas nas próprias orelhas, observação contínua das próprias mãos, olhar lateralizado, observar um objeto fora do ângulo normal do mesmo, e pulos e giros sem motivo aparente. ${ }^{57}$

Como o autista não recebe bem os estímulos sensoriais externos, pelo fato de estarem alterados, muitas vezes responde de forma desarmônica e "fora dos padrões" de comportamento, com expressão de seu desconforto por meio de gritos, fecharem os olhos ou taparem os ouvidos, movimentos bruscos dos braços e mãos, ou até tudo ao mesmo tempo, causando surpresa e constrangimento aos expectadores.

Tal quadro de agitação pode se apresentar durante as refeições, quando resistências a novas experiências, fobias, aversões e preferências alimentares, dificuldades de transições entre texturas, agitação, choro, agressividade e indisciplina à mesa podem ocorrer, não sendo incomum deficiências de vitamina B12, ácido fólico e selênio serem encontras nos autistas, ante suas peculiaridades de dinâmica intestinal e de absorção e processamento desses elementos. De igual forma, parece existir uma falha de metabolização da proteína da caseína, sendo desaconselhável alimentos com glúten e soja, bem como se deve estar sempre atento à alimentos potencialmente alergênicos para não ocorrer alguma neurotoxidade. ${ }^{58}$

A higiene bucal também costuma ser uma questão delicada aos autistas, ante sua aversão e hipersensibilidade a determinados procedimentos, aí incluindo a própria escovação.

Tais dificuldades são vivenciadas diariamente pela pessoa com TEA e seus familiares, desdobrando-se até mesmo em atividades corriqueiras, como estacionar em um local privativo para pessoas com deficiência. Em tais casos, não são raras as abordagens críticas por parte de populares por terem a limitada compreensão de que apenas pessoas com deficiência física possuem tal direito, o que, também, é induzido pelo símbolo demarcatório de tais vagas ser representativo de uma pessoa em cadeira de rodas.

\footnotetext{
56 O autismo é uma condição com inúmeras alterações, simultâneas e isoladas que podem determinar o grau e sub graus todos diferentes entre si. RODRIGUES, Ida Janete. Habilidades viso-perceptuais e motoras na Síndrome de Asperger. 2010. Tese (Doutorado) Psicologia Clínica - Instituto de Psicologia, Universidade de São Paulo, São Paulo, 2010. doi:10.11606/T.47.2010.tde-03092010-151245. Disponível em: https://teses.usp.br/teses/disponiveis/47/47133/tde-03092010-151245/publico/rodrigues2_do.pdf. Acesso em: 18 jun. 2019.

57 CAMPOS, Viviane. Autismo - do diagnóstico ao tratamento: as melhores orientações sobre o universo autista. In: PICCINATO, Ricardo (org.). Coleção Sindromes \& Distúrbios. São Paulo: Editora Astral Cultural, 2019. p. 20.

58 GUERINO, Leonardo. O Desafio do prato. Revista Autismo e Asperger- Leitura e Conhecimento, São Paulo, ano 2, n. 4, p. 20, 2019. ISSN 2596-0539.
} 
Apenas com a divulgação de informações a respeito do transtorno autista poderemos encarar e entender os indivíduos com suas singularidades.

Em suma, o autismo é, pois, considerado um transtorno do neurodesenvolvimento, com quadro de comprometimento de ordem psicológica e/ou mental, que afeta o funcionamento cerebral relacionado ao processamento e armazenamento dos estímulos sensórios e linguagem verbal e não verbal, prejudicando a capacidade de comunicação, imaginação e socialização, com conjuntos de sinais, sintomas e características nem sempre conhecidos, o que o afasta da classificação de doença por não se saber os mecanismos envolvidos e suas causas explícitas.

Por não ser uma doença, não existe nem cura nem medicamentos específicos, mas apenas tratamentos e terapias (como, por exemplo, terapia cognitivo-comportamental, comunicação por troca de figuras, fonoaudiologia, musicoterapia, terapia ocupacional e terapias assistidas por animais), a fim de proporcionar melhor qualidade de vida ao autista e sua família. Os remédios receitados costumam ser relacionados a outras dificuldades, como quando o indivíduo é extremamente agressivo ou possui outra comorbidade como epilepsia.

Resta patente que o TEA necessita de compreensão científica e social sobre o diagnóstico intelectual dos autistas, suas evoluções e possibilidades diante das dificuldades e embaraços cotidianos que eles, e suas famílias, vivem nas tentativas de serem inseridos nas atividades sociais básicas.

Devido tanto às suas dificuldades de socialização e comunicação, quanto à desinformação, o preconceito e a intolerância da grande maioria das pessoas, precisamos de mais informação e mais instrumentos (formais e informais) para exercer a solidariedade e garantir a proteção social desses indivíduos.

As mudanças sociais dependem, apenas, de nossa própria atuação, sendo certo que a inclusão dos autistas necessita muito da informação, cooperação e respeito dos seus direitos, com vistas a podermos viver todos a igualdade constitucionalmente prevista, com a correspondente dignidade reconhecida e preservada.

\section{Considerações Finais}

O autista, considerado pessoa com deficiência, passa por provações quando a questão de ser inserido de maneira igualitária na sociedade, juntamente a seus familiares, antes mesmo do diagnóstico, apesar de ser evidente a titulação dos mesmos direitos e garantias fundamentais que qualquer outro indivíduo, e a necessidade de leis nacionais expressas de reconhecimento e proteção.

Verifica-se, pois, a necessidade de se trabalhar socialmente para conscientização quanto aos direitos desses cidadãos, evitando-se comportamentos agressivos, intolerantes e desrespeitosos, frutos da simples falta de informação sobre o transtorno.

O autismo, ou transtorno do espectro autista, não é uma doença, nem adjetivo a ser utilizado, mas uma condição ou característica que varia em diversos níveis e que se manifesta por comportamentos diferenciados, geralmente incluindo atraso na linguagem associado a um comprometimento na comunicação, dificuldade de interação social, isolamento e padrões de comportamento repetitivo por meio de estereotipias.

Esse quadro alimenta e fundamenta, descabidamente, o preconceito e a exclusão de milhares de indivíduos apenas por manifestarem um comportamento diverso do considerado convencional, e as pessoas com o transtorno sofrem restrições cotidianas no exercício do seu direito fundamental de ser como é.

A deficiência, de forma geral, não pode ser vista, apenas, pelas limitações físicas ou psíquicas decorrentes de uma patologia ou condição, mas deve ser apresentada à sociedade como uma nova e desafiadora possibilidade de solidariedade, eliminando obstáculos, barreiras e preconceitos. 
A inclusão real das pessoas com deficiência, particularmente os autistas, está ainda muito longe de ser reconhecida e praticada, sendo necessárias políticas públicas específicas para o reconhecimento e exercício de, pelo menos, três direitos básicos.

O primeiro direito do autista corresponde ao direito à saúde, o que significa que tem direito ao seu diagnóstico precoce, sendo necessário a garantia do acesso fácil e rápido a neuropediatras ou psiquiatras infantis, com avaliação de um geneticista para se descartar a existência de uma síndrome genética. Esse primeiro passo possibilitará seu acompanhamento constante, com inclusão de terapias, estímulos e mesmo controle alimentar, o que influenciará sua socialização e desenvolvimento.

O segundo direito essencial dos autistas corresponde à inclusão social, educacional e de trabalho que, na verdade, também corresponde ao direito à saúde por fazerem parte do processo terapêutico e aperfeiçoamento de suas habilidades comunicativas e sociais.

A construção da autonomia das pessoas com deficiência, incluídos os autistas e os portadores de síndrome de Tourette e Transtorno de Déficit de Atenção com Hiperatividade (TDAH), dá-se, dentre outras formas, pelas cotas para seleção de profissionais, seja no serviço público, seja na iniciativa privada (art. 37 da Constituição Federal, artigo 5º $\$ 2^{\circ}$ da Lei 8112/90, e art. 93 da lei 8213/91).

No mesmo sentido, as escolas públicas e particulares devem seguir não apenas a Constituição, mas também a Lei de Diretrizes e Bases da Educação (art. $4^{\circ}$ da lei n. ${ }^{\circ}$ 9.394/96) e a Lei Brasileira de Inclusão (art. $4^{\circ}$ da Lei n. $\left.{ }^{\circ} 13.146 / 15\right)$ que garantem direitos educacionais às pessoas com deficiência, com punições a atos discriminatórios, sendo certo que a lei n. ${ }^{0}$ 13.409/16 determina cotas para pessoas com deficiência para o ingresso em universidades.

Receber uma criança autista na família ocasiona modificações claras e imediatas em suas prioridades e preocupações, juntamente à sensação de incapacidade e angústia com as perspectivas de futuro, inclusive de ordem financeira. Entendemos, pois, que o terceiro direito básico do autista corresponde à informação, assistência social, econômica, e terapêutica também de seus familiares, que devem contar com profissionais que os auxiliem a aprender as melhores formas de manejar as condutas e reconhecer as habilidades mais fortes dessas pessoas a fim de serem estimuladas.

Ademais, a situação especial de acompanhamento constante ao autista ocasiona, na grande maioria das vezes, a necessidade de vinculação exclusiva por parte, pelo menos, de um dos responsáveis, com abandono de sua vida profissional e remuneração respectiva. Defendemos, pois, a criação de benefício previdenciário próprio para situações como esta, com intuito de possibilitar a dedicação e o acompanhamento da pessoa com autismo.

Conclui-se, portanto, que, para que haja a inserção social do autista e todas as pessoas com deficiência, com a tolerância às limitações e características, é imprescindível que se aceite o direito das pessoas serem como são, cumprindo-se e aperfeiçoando-se a legislação já existente e, principalmente, mudando-se os corações e mentes para evoluirmos da tolerância ao verdadeiro respeito, e daí solidariamente nos movermos para cuidar, incentivar, apoiar e preparar para o mundo todo aquele que assim precisa, como se todos fôssemos o que verdadeiramente somos, qual seja, pais, mães, irmãos, irmãos, filhos e filhas uns dos outros.

\section{Referências}

AGUILAR FILHO, Sidney. Educação, autoritarismo e engenia = exploração do trabalho e violência à infância desamparada no Brasil (1930-1945). 2011. 364 p. Tese (Doutorado) - Universidade Estadual de Campinas, Faculdade de Educação, Campinas, São Paulo, 2011. Disponível em: http://www.repositorio.unicamp.br/handle/REPOSIP/251194. Acesso em: 14 jun. 2019. 
ALVES, José Carlos Moreira. Direito Romano. 15. ed. Rio de Janeiro: Editora Forense, 2012. v. I.

AMARAL, Carlos Eduardo Rios. Lei n. 12.764/2012: Direitos da Pessoa com Transtorno do Espectro Autista. Revista Jus Navigandi, 2016. Disponível em: https://jus.com.br/artigos/48333/lei-n-12-764-2012-direitos-da-pessoa-com-transtorno-do-espectro-autista. Acesso em: 15 jun. 2019. ISSN 1518-4862.

ANATALINO, João. O Deficiente na Cultura Greco-Romana - A Óptica Espartana. São Paulo: Recanto das Letras, 2017. Código do texto: T6141362. Disponível em: https://www.recantodasletras.com.br/artigos-de-educacao/6141362. Acesso em: 25 abr. 2019.

ASPERGER, Hans. Os "psicopatas autistas" na idade infantil - Parte 1. Rev. Latinoam. Psicopat. Fund., São Paulo, p. 314-337, jun. 2015. ISSN 1415-4714.

ASPERGER, Hans. Os "psicopatas autistas" na idade infantil - Parte 2. Rev. Latinoam. Psicopat. Fund., São Paulo, p. 519-538, jun. 2015. ISSN 1415-4714.

ASPERGER, Hans. Os "psicopatas autistas" na idade infantil - Parte 3. Rev. Latinoam. Psicopat. Fund., São Paulo, p. 704-727, jun. 2015.ISSN 1415-4714.

BRASIL. Constituição (1988). Constituição da República Federativa do Brasil. Brasília. DF. 1988. Disponível em: http://www.planalto.gov.br/ccivil_03/constituicao/constituicaocompilado.htm. Acesso em: 24 abr. 2019.

BRASIL. Constituição da República Federativa dos Estados Unidos do Brasil. Rio de Janeiro. RJ. 1934. Disponível em: http://www.planalto.gov.br/ccivil_03/constituicao/constituicao34.htm. Acesso em: 14 de jun. 2019.

BRASIL. Constituição dos Estados Unidos do Brasil. Rio de Janeiro. RJ. 1937. Disponível em: http:/ /www.planalto.gov.br/ccivil_03/Constituicao/Constituicao37.htm. Acesso em: 14 jun. 2019.

BRASIL. Constituição dos Estados Unidos do Brasil. Rio de Janeiro. RJ. 1946. Disponível em: https://www2. camara.leg.br/legin/fed/consti/1940-1949/constituicao-1946-18-julho-1946-365199-publicacaooriginal-1-pl.html. Acesso em: 14 jun. 2019.

BRASIL. Constituição da República Federativa do Brasil. Brasília. DF. 1967. Disponível em: http:/ /www.planalto. gov.br/ccivil_03/constituicao/constituicao67.htm. Acesso em: 14 jun. 2019.

BRASIL. Decreto N. 3.298, de 20 de dezembro de 1999. Política Nacional para a Integração da Pessoa Portadora de Deficiência. Brasília. DF. 1999. Disponível em: http://www.planalto.gov.br/ccivil_03/decreto/d3298. htm. Acesso em: 24 abr. 2019.

BRASIL. Emenda Constitucional n. ${ }^{\circ}$ 1, de 17 de outubro de 1969. Brasília. DF. 1969. Disponível em: http:// www.planalto.gov.br/ccivil_03/constituicao/Emendas/Emc_anterior1988/emc01-69.htm. Acesso em: 14 jun. 2019.

BRASIL. Emenda Constitucional n. ${ }^{\circ}$ 12, de 17 de outubro de 1978. Brasillia. DF. 1978. Disponível em: http:// www.planalto.gov.br/ccivil_03/constituicao/Emendas/Emc_anterior1988/emc12-78.htm. Acesso em: 14 jun. 2019.

BRASIL. Emenda Constitucional n. ${ }^{\circ}$ 41, de 19 de dezembro de 2003. Brasília. DF. 2003. Disponível em: http:// www.planalto.gov.br/ccivil_03/constituicao/constituicao.htm. Acesso em: 14 jun. 2019.

BRASIL. Emenda Constitucional n. ${ }^{\circ}$ 45, de 30 de dezembro de 2004. Brasília. DF. 2004. Disponível em: http:// www.planalto.gov.br/ccivil_03/constituicao/emendas/emc/emc45.htm. Acesso em: 14 jun. 2019.

BRASIL. Lei n. ${ }^{\circ}$ 12.764, de 27 de dezembro de 2012. Lei Berenice Piana. Política Nacional de Proteção dos Direitos da Pessoa com Transtorno do Espectro Autista. Brasília. DF. 2012. Disponível em: http://www.planalto. gov.br/ccivil_03/_ato2011-2014/2012/lei/112764.htm. Acesso em: 14 de jun. 2019.

BRASIL. Lei 13.146 de 06 de julho de 2015. Estatuto da Pessoa com Deficiência. Brasília. DF. 2015. Disponível em: http://www.planalto.gov.br/ccivil_03/_ato2015-2018/2015/lei/113146.htm. Acesso em: 24 abr. 2019. 
BRASIL. Lei 13.977 de 08 de janeiro de 2020. Lei Romeo Mion. Brasília. DF. 2020. Disponível em: http:/ /www. planalto.gov.br/ccivil_03/_ato2019-2022/2020/lei/113977.htm. Acesso em: 06 jun. 2020.

BRASIL. Secretaria Especial dos Direitos da Pessoa com Deficiência. Resultados Preliminares da AmostraCenso 2010. Brasília. DF. 2010. Disponível em: https://www.pessoacomdeficiencia.gov.br/app/indicadores/censo-2010. Acesso em: 19 jun. 2019.

CAMPANHOLE, Adriano; CAMPANHOLE; Hilton Lôbo. Todas as Constituições do Brasil - compilação dos textos, notas, revisão e índices. São Paulo: Atlas, 1971. Disponível em: http://biblioteca2.senado.gov. br:8991/F/?func=itemglobal\&doc_library=SEN01\&doc_number=000012720. Acesso em: 14 jun. 2019.

CAMPOS, Viviane. Autismo - do diagnóstico ao tratamento: as melhores orientações sobre o universo autista. In: PICCINATO, Ricardo (org). Coleção Síndromes \& Distúrbios. São Paulo: Editora Astral Cultural, 2019.

CUNHA, Danilo Fontenele Sampaio. A Justiça Sensivel. Perspectivas incomuns e possibilidades utópicas. Rio de Janeiro: Editora Lumen Juris, 2019.

DURANT, Will. História da Civilização: Nossa Herança Clássica. Rio de Janeiro: Editora Record, 1995. v. 2.

FARAH, Fabiana Barrocas Alves. Autismo: o desafio da inclusão na sociedade moderna. Revista Construir Noticias, Recife, ano 20, p. 40-43, 2020. ISSN 2236-3505. Disponível em: https://www.construirnoticias. com.br/autismo-o-desafio-da-inclusao-na-sociedade-moderna/. Acesso em: 01 mar. 2020.

FOUCAULT, Michel. História da Loucura na Idade Clássica. Trad. José Teixeira Coelho Netto. São Paulo: Perspectiva, 1978.

GARCIA, Vinicius Gaspar. As pessoas com deficiência na história do mundo. Rio de Janeiro: Bengala Legal, 2011. Disponível em: http://www.bengalalegal.com/pcd-mundial. Acesso em: 15 jun. 2019.

GARCIA, Vinicius Gaspar. Panorama da inclusão das pessoas com deficiência no mercado de trabalho no Brasil. Trab. educ. saúde, Rio de Janeiro, v. 12, n. 1, p. 165-187, abr. 2014. Disponível em: http://www.scielo. br/scielo.php?script $=$ sci_arttext\&pid=S1981-77462014000100010\&lng=pt\&nrm=iso. Acesso em: 18 jun. 2019. http://dx.doi.org/10.1590/S1981-77462014000100010.

GIDDENS, Anthony. Modernidade \& Identidade. Rio de Janeiro: Zahar, 2002.

GUERINO, Leonardo. O Desafio do prato. Revista Autismo e Asperger- Leitura e Conhecimento, São Paulo, ano 2, n. 4, p. 20, 2019. ISSN 2596-0539.

INSTITUTO BRASILEIRO DE GEOGRAFIA E ESTATÍSTICA. Censo Demográfico 2010: características gerais da população, religião e pessoas com deficiência. Rio de Janeiro: IBGE, 2010. Disponível em: https:/ / ww2.ibge.gov.br/home/estatistica/populacao/censo2010/caracteristicas_religiao_deficiencia/caracteristicas_religiao_deficiencia_tab_uf_xls.shtm. Acesso em: 19 jun. 2019.

MELO, Marilice Pereira Ruiz do Amaral. Inclusão na diversidade: a contribuição da espiritualidade e interdisciplinaridade. Educação: Fundamentos da Educação. Revista INTERESPE, São Paulo, n. 8, p. 100102, jun. 2017. ISSN 2179-7498. Disponível em: https://www.pucsp.br/interespe/revistas/downloads/ revista-8-interespe-jun-2017.pdf. Acesso em: 19 jun. 2019.

NISHIYAMA, Adolfo Mamoru; TEIXEIRA, Carla Noura. A evolução histórica da proteção das pessoas com deficiência nas Constituições brasileiras: os instrumentos normativos atuais para a sua efetivação. Revista de Direito Privado, São Paulo, v. 17, n. 68, p. 225-240, ago. 2016.

OLIVEIRA, Carolina. Um retrato do autismo no Brasil. Universidade de São Paulo. Revista Espaço Aberto USP, São Paulo, 2005. Disponível em: http://www.usp.br/espacoaberto/?materia=um-retrato-do-autismo-no-brasil. Acesso em: 19 jun. 2019. 
PESSOA, Amanda Carolina Santos. A diversidade brasileira, as minorias, o direito e a busca pela igualdade em contraposição às discriminações sociais. Revista do Direito Constitucional e Internacional, São Paulo, v. 106, ano. 26, p. 201-223, mar./abr. 2018.

RIO GRANDE DO SUL. Governo do Estado. Fundação de Articulação e Desenvolvimento de Políticas Públicas para Pessoas com Deficiência e com Altas Habilidades no Rio Grande do Sul - FADERS. Legislação Internacional. Rio Grande do Sul. Disponível em: http:/ /www.faders.rs.gov.br/legislacao/6. Acesso em: 18 jun. 2019.

RODRIGUES, Ida Janete. Habilidades viso-perceptuais e motoras na Sindrome de Asperger. 2010. Tese (Doutorado) Psicologia Clínica - Instituto de Psicologia, Universidade de São Paulo, São Paulo, 2010. doi:10.11606/T.47.2010.tde-03092010-151245. Disponível em: https://teses.usp.br/teses/disponiveis/47/47133/tde-03092010-151245/publico/rodrigues2_do.pdf. Acesso em: 18 jun. 2019.

SERRA, Dayse Carla Genero. Entre a esperança e o limite: um estudo sobre a inclusão de alunos com autismo em classes regulares. Tese (Doutorado) Psicologia, Pontifícia Universidade Católica do Rio de Janeiro, Rio de Janeiro, 2008. Certificação digital n 0510405/CB. Disponível em: https://www.maxwell.vrac.puc-rio. br/13415/13415_1.PDF. Acesso em: 15 jun. 2019.

SILVA, Otto Marques da. A Epopeia Ignorada: A Pessoa Deficiente na História do Mundo de Ontem e de Hoje. São Paulo: CEDAS, 1987. Disponível em: https://issuu.com/amaurinolascosanchesjr/docs/-a-epopeia-ignorada-oto-marques-da-. Acesso em: 22 abr. 2019.

SPÍNOLA, Grasielly de Oliveira. Autismo: o ideal e o real na efetivação da decisão jurisdicional que implementa políticas públicas. Revista Brasileira de Políticas Públicas, Brasília, v. 4, n. 1, p. 55-65, 2014. Disponível em: https://www.publicacoesacademicas.uniceub.br/RBPP/article/view/2756/pdf_1. Acesso em: 22 jun. 2019.

TABOSA, Agerson. Sociologia Geral e Jurídica. Fortaleza: Qualygraf Editora e Gráfica, 2005. 
Para publicar na revista Brasileira de Políticas Públicas, acesse o endereço eletrônico www.rbpp.uniceub.br

Observe as normas de publicação, para facilitar e agilizar o trabalho de edição. 